\title{
TRADICIÓN DOCTRINAL Y EJEMPLAR DE LOS ÉTATS DU MONDE EN EL RIMADO DE PALACIO DE PERO LÓPEZ DE AYALA*
}

\author{
Hugo O. BizzarRI \\ Université de Fribourg \\ hugo.bizzarri@unifr.ch
}

En las coplas 191 a 728 del Rimado de Palacio, Pero López de Ayala realiza una crítica a los estados, es decir, a los diversos estamentos de la sociedad. No es la primera vez que en la literatura española encontramos algo similar. De hecho, Juan Manuel hizo también un relevamiento de ellos en el llamado Libro de los estados, aunque hay algo que diferencia notablemente ambos textos: Juan Manuel describe los deberes y obligaciones de cada estado; Ayala realiza una crítica de ellos, que por momentos se acerca a la sátira ${ }^{1}$.

E. Bryan Strong analizando esta sección señaló como fuente la Summae virtutum et vitiorum de Guillermo Perrault, especialmente para la sección dedicada a los mercaderes (cc. 298-313)2 , que recientemente Giuseppe Mazzocchi ha reconfirmado ${ }^{3}$. Germán Orduna en las notas a su editio maior del poema ayalino señalaba que esta crítica a los estados seculares es «asunto

\footnotetext{
*Este trabajo se enmarca dentro del proyecto FFI2012-32265, La fábula esópica en la literatura española del siglo XIV, subvencionado por el Ministerio de Economía y Competitividad de España.

${ }^{1}$ Por eso Kenneth R. Scholberg (Sátira e invenctiva en la España Medieval, Madrid, Gredos, 1971, pp. 179-189) analiza el Rimado a continuación del Libro de buen amor. Ian R. Macpherson y Robert Brian Tate en su edición de El Libro de los estados (Madrid, Castalia, 1991, p. 10) advirtieron que entre la obra de Juan Manuel y la de Ayala hay una enorme distancia, pero la basaron en que Juan Manuel reproduce el debate entre el imperium y el sacerdotium.

${ }^{2}$ E. B. Strong, «El Rimado de Palacio: algunas observaciones sobre las fuentes de la sátira de los estados de López de Ayala», en Estudios dedicados a Leslie Brooks, Barcelona, Puvill, 1984, pp. 207222; véase también del mismo «The Rimado de Palacio: Aspects of López de Ayala's Narrative Style», en Modern Language Studies, 22:1 (1986), pp. 53-61.

${ }^{3}$ Giuseppe Mazzocchi, «I mercanti del Rimado de Palacio: elementi satirici in Pero López de Ayala», en 'Però convien ch'io conti per disdigno'. La satira in versi tra Italia e Spagna dal Medioevo al Seicento, ed. de Antonio Gargano, Nápoles, Liguori, 2011, pp. 31-54.
} 
de vasta tradición en la literatura medieval tanto latina como vulgar» ${ }^{4}$, idea que volvió a expresar en su editio minor: «El primer bloque 'exemplar' es la exposición de los Males del Mundo (cc. 191-423), el que más estrictamente puede tener contactos con los 'miroirs' y los 'Livres des manières' corrientes en el siglo XIV» ${ }^{5}$. Se trata de una aguda intuición del investigador argentino que seguí en mi edición del poema ayalino. Ahí señalaba yo un entronque del Rimado con la corriente de los états du monde e indicaba su proximidad con un poema de Rutebeuf $f^{6}$. En el presente trabajo quisiera profundizar en esta pista.

\section{La corriente de los États du monde}

Ruth Mohl dedicó un excelente libro a definir y describir la historia de lo que ella no dudó en caracterizar como un género literario ${ }^{7}$. Para la autora hay un conjunto de obras que comparten rasgos que las caracterizan como pertenecientes a un género dedicado a analizar los diversos estamentos de la sociedad medieval. Se trata de una literatura que puede aparecer tanto en prosa como en verso, cuyo objetivo fundamental es el de realizar un catálogo o listado gradual de los estados. Presentan estos textos una visión de la sociedad en la que se destacan sus virtudes y vicios, aunque de ambos -y esto es punto clave- se suele hacer más hincapié en los defectos de cada estado más que en sus virtudes, realizándose así una crítica de la sociedad que por momentos se acerca a la sátira.

El atractivo de estos textos y su pervivencia a lo largo de toda la Edad Media se debió a que ellos no presentaron nunca una visión monolítica de la sociedad feudal, pese a que durante toda la Edad Media se mantuvo el orden de los tres estados descriptos por Georges Duby ${ }^{8}$. Por el contrario, cada autor, sobre la base del examen gradual de los estados, podía presentar su propio punto de vista de la sociedad, hacer su propia crítica. Como bien señala $\mathrm{Mohl}^{9}$, cada autor se servía de un esquema general para volcar su propia experiencia de la sociedad feudal.

${ }^{4}$ Pero López de Ayala, Rimado de Palacio, ed. de Germán Orduna, Pisa, Giardini Editori, 1981, pp. 31-32.

${ }^{5}$ Pero López de Ayala, Rimado de Palacio, ed. de Germán Orduna, Madrid, Castalia, 1987, p. 43.

${ }^{6}$ Pero López de Ayala, Rimado de Palacio, ed. de Hugo O. Bizzarri, Madrid, Real Academia Española, 2012, pp. 357-360.

${ }^{7}$ Ruth Mohl, The Three Estates in Medieval and Renaissance Literature, New York, Columbia UP, 1933.

${ }^{8}$ Georges Duby, Les trois ordres ou l'imaginaire du féodalisme, París, Gallimard, 1978.

${ }^{9}$ Mohl, ob. cit., p. 7. 
Hay en todos los autores que recurren a este género una visión negativa de la sociedad: describen la decadencia de cada uno de los estados del mundo. Dicha decadencia no es ni económica ni estructural, sino moral. La sociedad en su conjunto está presa del pecado de la codicia, la cual hace nacer la mentira y hasta incurrir al hombre en la usura. En consecuencia, hay un convencimiento de que cada estado no responde a la función que le ha sido asignada en la sociedad.

Esta doctrina estaba acompañada de una profusa ejemplificación. Es aquí donde se mostraba la habilidad del autor y su originalidad, creando vivos cuadros de costumbres como este en el que Rutebeuf describe la forma de accionar de los mercaderes:

Or i a gent d'autres manieres
qui de vendre sont coustumieres
de choses plus de cinq cens paires
qui sont au monde necessaires.
Je vous di bien veraiement.
ils font maint mouvais serement
et si jurent que lot denrees
sont et bones et esmerees
tel foiz que c'est mençonge pur
si vendent a terme, et usure
vient tantost et termoierie
qui sont de privee mesnie;
lors est li termes achatez
et plus cher venduz li charez ${ }^{10}$.

Rutebeuf no cuestiona el orden de la sociedad: los mercaderes tienen una función clara y necesaria en ella; pero lo que critica es su codicia, que acarrea la mentira y la usura. Estos cuadros de costumbres dejan paso a vivos diálogos que otorgan a las piezas un carácter dramático. Vuelvo sobre Rutebeuf para insertar su crítica a los oficiales de la justicia:
Or m'estuet parler de genz laïes, qui resont plaie d'autres plaies. provost et bailli et maieur sont communement li pieur. si com Covoitise le vost; quar je regart que li provost,

\footnotetext{
${ }^{10}$ Rutebeuf, «L'état du monde», en Oeuvres complètes, ed. de Michel Zink, I, París, Garnier, 1989, vv. 121-133.
} 


\begin{abstract}
qui acenssent les provostez.
Que il plument toz les costez

a cels qui sont en lor justice,

et se deffendent en tel guise:

«Nous les acenssons chierement,

si nous convient communement,

font il, partout tolir et prendre

sanz droit ne sanz reson atendre;

trop avrions mauves marchie

se perdons en nostre marchie» (vv. 91-106).
\end{abstract}

Los oficiales venden la justicia presos de la codicia (covoitise). Pero no le importa a Rutebeuf describir tanto la forma de trabajo de este gremio como poner en primer plano la justificación que ellos hacen de sus actos. La mentira surge de forma evidente.

Los états $d u$ monde, por tanto, no cuestionaban el orden impuesto en la sociedad, ni trataban de encontrar un justificativo a los diversos estados; más bien estas obras denunciaban una crisis de valores basada en la mentira y en la codicia. Sus testimonios más antiguos se manifiestan en la literatura latina a partir del siglo XII. Se trata de poemas salidos de un ámbito escolar o eclesiástico, motivo por el cual el grupo social más atacado es el clero. El primero de ellos es un poema latino titulado De statibus mundi que ha sido atribuido a Gautier de Châtillon ${ }^{11}$, en el cual el autor denuncia la instauración de los pecados en el mundo. En su catálogo cobran relevancia los estados eclesiásticos, pues son los prelados uno de los estados más afectados por esta situación. Destaca en su poema la apetencia al dinero que hace olvidar a cada estado sus deberes. Poco posterior, hacia 1220, otro poema latino expresará la misma opinión, Sermones nulli parcentes ${ }^{12}$. Su editor, Theodor von Karajan, adscribió este texto a un autor perteneciente a la orden de los predicadores del círculo de Federico II Hohenstaufen ${ }^{13}$. La obrilla, de carácter literario más ambicioso que la anterior, consta de un prólogo en prosa, otro en verso y de 28 capítulos. Se realiza aquí un relevamiento de los estados de la sociedad más detallado que aquel que se halla en el poema De statibus mundi: primero se ocupa de los clérigos (caps. 1-14), luego de los seglares (caps. 15-28). Dentro de este, cobra relevancia un nuevo grupo, el de las mujeres, al que le

\footnotetext{
${ }^{11}$ Fue publicado por W. Müldener, Die Zehn Gedichte des Walther von Lille gennant von Châtillon, Hannover, Carl Rümpler, 1859, pp. 7-11.

${ }^{12}$ Theodor von Karajan, «Buch der Rügen», en Zeitschrift für deutsches Altertum, 2 (1842), pp. 6-92.

${ }^{13}$ Karajan, ob. cit., pp. 10-11.
} 
dedica dos capítulos (caps. 27-28) ${ }^{14}$. En el último, vuelve sobre el estamento de los religiosos, al instar a los predicadores a no olvidar su oficio de servidores de Cristo.

En el siglo XIII otro poema que comienza Frequenter cogitans de factis hominum, de autor anónimo y que Du Méril tituló Des diverses classes d'hommes, expone largamente los males del mundo ${ }^{15}$. Ningún grupo escapa a la sátira de este poeta: nobles, caballeros, soldados y campesinos, aunque es claro que su blanco preferido son los eclesiásticos. Asoma ahora un nuevo grupo social, el de los mercaderes (mentirosos, codiciosos y cornudos), que se transformará con el tiempo en blanco preferido de la crítica a los seglares. En los siglos XIII y XIV aparecerán otros textos como el poema titulado Viri fratres, servi Dei que lamenta que todas las clases hayan olvidado la $\mathrm{fe}^{16}$; o los poemas De diversis ordinibus hominum, Contra avaros, etc. ${ }^{17}$. Mención especial merece el poema Tractatus de lucis scrutinio atribuido a John Gower (1330-1408), contemporáneo de Ayala ${ }^{18}$. Gower aplica el género al problema del Cisma de la Iglesia. El mundo está en penumbras, por ello hay dos papas en Roma. Esta situación de crisis se proyecta sobre toda la sociedad que anda como ciega. Los clérigos cometen simonía, las órdenes de clausura están presas de la envidia; los presbíteros malgastan sus días en la taberna. Luego pasa revista a los estados seglares: reyes, caballeros, jueces, mercaderes y el pueblo estarán envueltos en esta crisis. En conclusión, el mundo está ciego y llega a la prevaricación: «Omnis orbe status modo stat quasi praevaricatus» (p. 359). El poema termina con una plegaria pidiendo a Dios que devuelva la luz al mundo:

Tu qui formasti lucem, tenebrasque creasti, crimina condones, et sic tua lumina dones. In terram sero tunc quando cubicula quaero, confer candelam, potero qua ferre modelam (p. 359).

Poemas de este estilo no sólo circularon de manera independiente, sino que también se incluyeron dentro de otras obras mayores.

\footnotetext{
${ }^{14}$ Véase Mohl, ob. cit., p. 20.

${ }^{15}$ Edélstand Du Méril, Poésies populaires latines du moyen âge, París, Firmin Didot, 1847, pp. 128136.

${ }^{16}$ Du Méril, ob. cit., pp. 136-144.

${ }^{17}$ Mohl, ob. cit., pp. 21-34.

${ }^{18}$ Editado por Thomas Wrigth, Political Poems and Songs Relating to English History, Londres, Longman Green Longman and Roberts, 1859, I, pp. 356-359.
} 
Las literaturas vulgares no iban a ser indiferentes a esta forma de sátira social. A partir del siglo XII comenzaron a aparecer obras en los diversos idiomas vernáculos, especialmente en Francia, donde tuvo una floración excepcional ${ }^{19}$. Pero el paso a las formas vulgares trajo aparejada una modificación del género: se fue focalizando cada vez más la crítica a un grupo determinado. Aparecieron así las profesiones, los artesanos, abogados y mercaderes. Por otra parte, se aguzó el espíritu satírico creando verdaderas representaciones en las que aparece el diálogo o la descripción de la forma de actuar de los gremios.

El texto romance más antiguo es Le Livre de manières de Étienne de Fougères (ca. 1174) $)^{20}$, personaje que trabajó en la cancillería de Enrique II Plantagenet y que al final de su vida llegó a ser obispo de Rennes (1168-1178), período en el cual parece haber escrito su obrilla. Este autor describe largamente la condición de los estados del mundo con la intención de que su obra sea un espejo en el que las personas pueden conocer las costumbres del mundo, qué es lo que se debe reprobar y qué lo que se debe hacer. En su visión de los estados, la obra resume los ideales políticos y sociales que reproducen el modelo trifuncional de la sociedad:

[L]i clerc deivent por toz orer,

li chevalier sanz demorer deivent defendre et ennorer, et li paisant laborer ${ }^{21}$.

Cada grupo social tiene una función en el mundo, pero ella se halla subvertida. Sin embargo, Étienne de Fougères no critica a la Iglesia, al contrario, la considera cabeza de la sociedad y, por tanto, los caballeros deben estar dispuestos a defenderla (vv. 597-599). Como ya había sucedido en la tradición latina, el autor dedica una sección a las mujeres, dando espacio a la descripción de las lesbianas (vv. 1097-1124).

Hacia 1252 Rutebeuf, personaje del cual se sabe muy poco, salvo que estuvo mezclado en la crisis de la Universidad de París del año $1252^{22}$, escribió dos poemas que expresan una visión negativa del mundo. El primero es el llamado Les plaies du monde, en el cual describe las tres llagas del mundo:

${ }^{19}$ Jean V. Alter, Les origines de la satire anti-bourgeoise en France (Moyen Àge-XVI siècle), Ginebra, Librairie Droz, 1966.

${ }^{20}$ Anthony Lodge, «The Literary Interest of the Livre des manières of Étienne de Fougères», en Romania, 93:4 (1972), pp. 479-497.

${ }^{21}$ Étienne de Fougères, Le Livre des manières, ed. R. Anthony Lodge, Ginebra, Librairie Droz, 1979, vv. 673-676.

${ }^{22}$ Rutebeuf, ed. cit., I, pp. 2-32. 
ellas se reducen a una, la avaricia, especialmente poseída por el clero. El segundo poema es L'état du monde, en el cual observa los cambios que experimenta el mundo y él quiere hablar de ellos. Aflora una vez más una visión pesimista: el autor se lamenta que ya no se trabaje para el prójimo sino para el provecho propio; los religiosos, que deberían vivir honestamente, están cautivos de la codicia, viviendo del patrimonio de la Iglesia; los caballeros no cumplen con su misión de defender la Iglesia y artesanos y mercaderes se entregan a la usura.

Pero, como bien sostuvo Alter «la forme dominant de la satire antibourgoise pendant le deuxième âge féodal sera la satire professionelle $\rangle^{23}$. Por tanto, comienzan a ser más frecuentes visiones parciales de la sociedad; mercaderes, maestros, artesanos, usureros, abogados, clérigos y caballeros irán ocupando la atención por igual. De la segunda mitad del siglo XIII se halla un poema titulado Les dits des avocats et des notaires, una tremenda sátira a los juristas y en la cual el autor toma parte por los villanos ${ }^{24}$ : «Conter vos veil des avocats, / des procureus et des notaires / et de ceus qui ne prisent gueres / nule gent s'eus meïnes non» (vv. 16-19). El poeta pinta en vivos diálogos la forma deshonesta que tienen los juristas de ganar el dinero; de esta forma, denuncia los fraudes que suelen cometer: «Einsi se moquent et estrivent / de ceus qu'il ont nuet grevé / dont ne sunt il larron prové?» (vv. 374-376).

Le dit des paintres muestra a pintores y teñidores como virtuosos de la falacia $^{25}$. ¿Quién mejor que ellos para desfigurar la realidad, para hacerla resplandecer de otra forma? Se trata de virtuosos, pero personas de falso corazón: «Vous savez qui sont une gens. / qui semblent estre dous et gens / et de bonne nature, / mès les cuers ont faus et puans» (p. 101). Ellos pueden inundar las calles de Flandes, son más poderosos que reyes y condes. A pesar de dedicarles la pieza entera, el poeta no puede olvidar a los abogados y escribanos, pintores con la palabra: «Mout d'escrivains, je n'en dout pas, / sont paintres, et tous avocas / paingnent en leur parole» (p. 98).

En definitiva, este grupo compacto de poemas presentaba una visión negativa de la sociedad contemporánea. En ellos se combinaban tradición doctrinal y ejemplar, en la cual no se destaca tanto la originalidad de su pensamiento como los vivos retratos.

\footnotetext{
${ }^{23}$ Alter, ob. cit., p. 23.

${ }^{24}$ Gaston Rayonaud, «Des avocats, de la jument au diable, de Luque la maudite. Trois dits tirés d'un nouveau manuscrit de fableaux», en Romania, 12 (1883), pp. 209-229.

${ }^{25}$ Archille Jubinal, «Le dit des paintres», en Nouveau Recueil de contes, dits, fabliaux et autres pièces inédites des XIII , XIV et XV $V^{e}$ siècles, París, Chez Edouard Pannier, 1839, I, pp. 96-101. Sobre este gremio, véanse las páginas que le dedica Michel Pastoureau, Una histoire symbolique du Moyen Âge occidental, París, Éditions du Seuil, 2004, pp. 194-220.
} 


\section{La adaptación de Pero López de Ayala de un género a la crisis caste- llana del siglo XIV}

Las literaturas hispánicas están casi ausentes del libro de Mohl. De hecho, en un par de líneas despacha la presencia del género de los états du monde en el Libro de Alexandre y en el Speculum vitae humanae de Rodríguez de Arévalo $^{26}$. Deja de lado también la poesía gallega con sus cantigas de escarnio y maldecir, la crítica a la Iglesia y al Papado que hace Juan Ruiz en el Libro de buen amor (cc. 490-512) y al exponente más destacado del género en la Península, Pero López de Ayala.

El Rimado de Palacio ha sido estudiado con frecuencia como un testimonio de la crisis del siglo $\mathrm{XIV}^{27}$. Ayala fue un gran observador de la realidad de su tiempo, pero también una persona con una vasta formación: fue instruido por su tío Pérez Gómez Barroso para que ingresara a las órdenes religiosas; tuvo una formación militar y administrativa; y sus dotes de escritor lo elevaron al cargo de cronista real. Su cultura literaria debió de ampliarse con motivo de sus largas estancias en Francia, como embajador del gobierno español ante la corte papal de Aviñón y ante los reyes Carlos V y Carlos VI de Francia $^{28}$. Es por eso que la literatura de los états du monde creo que no pudo ser desconocida para el canciller.

A lo largo del Rimado de Palacio Ayala se sirve del vocablo 'estado' otorgándole diversas significaciones ${ }^{29}$. Lo puede utilizar en un sentido general para designar 'una situación' o 'grado de alguna cosa'. Al hablar de la situación asfixiante en que ha llegado la presión de los señores, indica: «e a tal estado son llegados ya los fechos» (c. 243c) o cuando Job explica a Sofar que está libre de culpa el hombre difamado: «ca su meresçimiento lo traxo a tal estado / que d'el rien los omnes e anda asi cuitado» (c. 1091cd) ${ }^{30}$. También puede designar una condición momentánea de la vida: «Fuyen como sonbra e nunca en un estado / anda mi vida breve» (c.1118ab); «Mas veo yo al omne

\footnotetext{
${ }^{26}$ Mohl, ob. cit., pp. 33-34.

${ }^{27}$ Franco Silva y Manuel Romero Tallafigo, «Un testimonio de la crisis de la sociedad feudal del siglo XIv: el Rimado de Palacio de Pero López de Ayala», en Hispania, 41 (1981), pp. 485-514; Michel García, Obra y personalidad del Canciller Ayala, Madrid, Alhambra, 1982; Ignacio González Álvarez, El Rimado de Palacio: su visión de la sociedad entre el testimonio y el tópico, Vitoria, Diputación Foral de Álava, 1990; Eugenio M. Olivares Merino, «El retrato de la sociedad medieval en The Canterbury Tales y el Rimado de Palacio», en Medioevo y Literatura (Actas del V Congreso de la Asociación Hispánica de Literatura Medieval, Granada, 27 sept.-1 oct. 1993), ed. de Juan Paredes Núñez, Granada, Universidad de Granada, 1995, III, pp. 491-497.

${ }^{28}$ Remito para ello al detallado estudio de Antonio Serrano de Haro, El embajador don Pero López de Ayala (1332-1407), Madrid, Ministerio de Asuntos Exteriores, 2001.

${ }^{29}$ El concepto había ya sido el objeto del título XXIII de la Partida IV.

${ }^{30}$ Las citas del Rimado están hechas sobre la edición de Bizzarri, ed. cit.
} 
muerto e consumido, / non lo veo despues ni el a mi nunca vido / e aquel primero estado» (c. 11211c).

Más frecuente es su uso para designar un estamento social: «En todos los estados hay perigros asaz» (c. 297a); «Asaz veo de perigros en todos nuestros estados» (c. 314a); «[...] el estado es grande mas sienpre con gemido» (c. 384b); «¿Cuál estado puede en aqueste mundo ser, / si non con grant perigro e con poco plazer» (c. 492ab); «Si tu piensas la vida de este mundo mortal / e cuanto tienpo dura e cuanto ha de mal, / e non sabe la ora cuando sera nin cual, / ni en que estado te falle, bueno o comunal» (c. 551).

En un sentido más específico la voz 'estado' puede ser utilizada para designar un estamento social particular. Todos los ejemplos se reducen a su aplicación del estado de Papa: «En el tienpo muy santo non podian aver / uno que este estado se atreviese a tener» (c. 198ab); «Con grant piedat, sospiros et lloro, / e con çollosos La Eglesia vos pide / que este estado que es su tesoro / de unico papa por vos non se olvide» (c. 864ad).

Con menos frecuencia, pueden hallarse algunas locuciones, como 'estado de inocencia': «Si Eva, nuestra madre, aquel fruto non viera, / nunca la cobdiçiaria nin d'ella comiera, / del estado de inoçençia asi nunca cayera» (c. 1248ac); o 'cobrar estado' con el sentido de recobrar el favor de Dios: «[...] e el gentil mejor / donde cobro estado a Dios en su favor» (c. 1438cd). Ayala utiliza, pues, la voz 'estado' para referirse a los estamentos sociales. Su frecuencia es mucho más asidua que en autores precedentes, como el autor del Libro de Alexandre o Juan Ruiz.

La sección dedicada a la crítica a los estados en el Rimado de Palacio posee una elaborada estructura. Se inicia con dos coplas que sirven de introducción al tema:

Esta el mundo en quexa e en tribulaçion, los nuestros regidores son d'ello ocasion, e asi cresçen los males muchos ademas son, ca cobdiçia les çiega todo su coraçon.

Los fisicos lo dizen, si bien me viene emiente, desi la cabeça duele, todo el cuerpo es doliente, e agora, ¡mal pecado!, hoy es este açidente, ca nuestro mayoral en todo mal se siente (cc. 191-192).

Comienza Ayala denunciando una crisis en el mundo que tiene su principio en las ramas altas del poder. Conforme a la concepción corporativista 
que él expresa, la crisis se transmite a toda la sociedad. A partir de aquí inicia su análisis de los diversos estamentos sociales. En principio, examina la situación de la Iglesia (cc. 193-233), sección en la que hablará del Papa y del clero en general (cc. 221-231) como una forma de describir la situación de la cristiandad. Luego le sigue el análisis del gobierno seglar (cc. 234-296): reyes, príncipes y emperadores (cc. 234-259), caballeros (cc. 260-271) y privados (cc. 272-296). Sin salir del ámbito laico, pero ya fuera de la esfera del gobierno, Ayala pasa revista a las principales profesiones (cc. 297-371): mercaderes (cc. 298-313), juristas (cc. 325-336), caballeros (cc. 338-341), diversos funcionarios de la justicia (cc. 342-363), los arrendadores (cc. 364371) y los judíos, a los cuales no les dedica una sección en especial, pero cuya forma de acción denuncia en varios pasajes. El análisis de la sociedad se cierra con una reflexión sobre las virtudes (cc. 372-384) que desemboca en una plegaria (cc. 385-422).

El análisis que realiza Ayala no se escapa a la visión general de la sociedad que presentaba la literatura de los états du monde, aunque el canciller la adecua a la encrucijada castellana del siglo XIV. El origen de todos los males es, siguiendo esta tradición, la codicia y así lo expresa en las coplas de introducción («cobdiçia les çiega todo su coraçon», c. 191d). Esta apetencia desenfrenada por el dinero que achaca Ayala a las cúpulas de la sociedad la destaca en cada uno de los estados que analiza. Ella ha matado el espíritu del primitivo cristianismo que alentaba en el estado de Papa. El Pontífice está llamado a retomar el legado de San Pedro que supieron llevar sus sucesores, Lino, Cleto y Clemente. A esa época gloriosa de virtudes, Ayala opone la situación actual de la Iglesia, cuya decadencia es la codicia: «Agora el papadgo es puesto en riqueza» (c. 197a). Critica Ayala la opulencia en la que viven los papas actuales.

El clero no escapa a esta situación, de quien delata su avidez. Gracias al dinero se obtienen cargos y dignidades:

Cuando van a ordenarse tanto que llevan plata, luego pasan examen sin ninguna barata, ca nunca el obispo por tales cosas cata, luego les da sus letras con su sello e data.

Non saben las palabras de la Consagraçion, nin curan de saberlas, nin lo han a coraçon; si puede aver tres perros, un galgo e un furon, clerigo del aldea tiene que es infançon. 
LA TRADICIÓN DOCTRINAL Y EJEMPLAR DE LOS ÉTATS DU MONDE EN EL RIMADO...

Luego los feligreses le catan casamiento

de alguna su vezina, ¡mal pecado!, non miento, e nunca por tal fecho resçiben escarmiento, ca el su señor obispo ferido es de tal viento (cc. 223-225).

El oficio de religioso es, pues, una forma de ascenso social. Hace aquí Ayala un vivo retrato del sacerdote de pueblo que no sólo es atrapado por el pecado de la codicia, sino también por el de lujuria, pues aceptan tener por barraganas a mujeres de su feligresía. Dos coplas le sirven para cerrar esta visión desoladora de la situación general de la Iglesia. En la primera (c. 232) indica que la caridad y el amor al prójimo han desaparecido de la cristiandad. La crisis de la comunidad cristiana es de carácter moral. En la segunda (c. 233) eleva una plegaria a Dios para que ayude a la humanidad a enmendar estas conductas.

El mal gobierno del reino produce el despoblamiento de la tierra (c. 234). La función especial del rey es la de mantener sus reinos en paz y en sosiego (c. 238), pero sobre todo velar por la justicia de sus reinos:

Dios les de buen consejo que lo quieran creer e puedan en sus tierras justiçia mantener; segunt que lo yo entiendo, mucho es menester, que veo los sus pueblos sospirar e gemer (c. 240).

Lo que Ayala dice sobre los reyes lo aplica también a los caballeros. Retrata el Canciller su codicia: ellos son los servidores del rey y, por tanto, piden los pechos que el monarca establece, pero la codicia hace que exijan el doble de lo que solicita el rey y para esto se valen de los judíos (c. 262). La consecuencia es, una vez más, la despoblación del reino: «Do moravan mil omnes non mora ya trezientos» (c. 261a). En su apetencia de poder construyen grandes castillos en las afueras de las villas para protegerse (c. 268), pero antes de que los terminen les llega la muerte (cc. 269-271).

La función de los privados es la de aconsejar al rey, pero ellos no cumplen con su deber. Por el contrario, observan de qué lado se inclina la voluntad del monarca y así lo aconsejan mirando su beneficio:

Cuando en el connsejo la cuestion es propuesta, luego cata el privado a cual cabo se acuesta la voluntad del rey, e va por esta cuesta cuidando a su casa llevar buena respuesta (c. 273). 
La codicia se apodera de sus consejos: lo único que les interesa es acopiar riquezas. El pasaje lleva a Ayala a hacer una larga reflexión sobre las obligaciones del consejero (cc. 276- 296). En este sentido, el canciller propugna un consejo formado por muchos y por los hombres más preparados del reino ${ }^{31}$.

La sección dedicada a las profesiones (cc. 297-336) también se inicia con una copla general, que indica que en todos los estados se corre el riesgo de no cumplir con la función que le está impuesta:

En todos los estados hay prigros asaz, prinçipes e señores, en guerra e en paz, este mundo los turba e muy quexados faz', quien cuida que ha sosiego asaz tiene de agraz (c. 294).

Esta sección se ocupará de demostrar cómo el pecado de la codicia se expande sobre todo el resto del reino. Los mercaderes, por naturaleza mentirosos, sólo se preocupan en duplicar sus ganancias, traspasando con ello un precepto estipulado en el Antiguo Testamento: «Nunca ternas dos pesos, un pequeño otro mayor» (c. 308b) (Deuteronomio 25, 13-16). Este pecado es ya tan común que nadie se espanta de esta codicia (c. 313).

El siguiente grupo, el de los juristas (cc. 315-336), manipulan la justicia para su provecho («en el dinero tienen todos sus finos amores», c. 315c). Vuelve, entonces, sobre el estado de los caballeros (cc. 338-341). El error de este grupo social es de no hacer la guerra, procurando más bien su provecho, afligiendo al pueblo («sobre los pobres sin culpa se acostunbran mantener», c. 339d). La sección dedicada a la justicia (cc. 342-363) retoma lo tratado sobre los juristas (cc. 315-336). Si bien ella trae la paz tan necesaria al reino (c. 346), sostiene que no protege a los pobres. Finalmente, recae sobre el estado de los arrendadores (cc. 364-371), que no es sino otra forma de hablar de la justicia.

Hay dos grupos sociales que Ayala no retrata de forma independiente; sin embargo, ellos se hallan presentes en las diversas críticas a la sociedad. Uno es el de los judíos, que aparecen como prestamistas, actividad que los arrastra a la usura. El otro es el de los villanos a los que Ayala coloca siempre como objeto de la codicia de las otras clases más poderosas.

Esta sección del Rimado termina con una extensa reflexión sobre la dificultad de ejercer las virtudes (cc. 373-384): franqueza, templanza, humildad, fortaleza, apercibimiento, son las virtudes sobre las cuales se debe basar el funcionamiento de la sociedad. Como cierre, coloca Ayala el primer poema penitencial, que

\footnotetext{
${ }^{31}$ Para este tema remito a Hugo O. Bizzarri, «Consejos y consejeros, según Pero López de Ayala», en e-Spania, 12 (2011). Enlace: <http://e-spania.revues.org/20603> [fecha consulta: 18/02/2015].
} 
el copista de $N$ (Ms. BNE 4055) denominó 'Rogaría' (cc. 385-422): en él pide a Dios que lo socorra («iacorreme, Señor, que pueda bien acabar!», c. 398d). La solución es la oración (c. 410) a través de la cual Dios puede socorrer al hombre. Expresa aquí Ayala una idea que luego ejemplificará con la paráfrasis final de Job; todas estas penas son pruebas Dios que impone al hombre:

Muchos penan grant tienpo en la tribulaçion

porque sea provada su firme oraçion,

e sufren penitençia, mas y viene sazon

que llega luego Dios con su consolaçion (c. 419).

A esto le seguirá uno de los episodios más famosos del libro: el llamado 'Los fechos del palacio' (cc. 423-476) y una larga reflexión sobre el poder temporal (cc. 477-728), que se alejan de este tipo de literatura.

Esta doctrina va acompañada de numerosos exempla con los cuales Ayala dramatiza la situación de Castilla ${ }^{32}$. Tampoco esto escapa a los tópicos del género de los états du monde, pero lo original en el canciller es que él no repite aquí ningún relato preexistente. Sus cuadros no son sino fiel retrato de la realidad política y social de Castilla y de Europa.

El primero de esos exempla está destinado a hablar de los orígenes del Cisma para explicar la crisis que vive el Papado. Se trata de la elección de Urbano IV (c. 198-211). Ayala trabaja aquí los exempla como si fueran cuadros de costumbres, por eso, se pasa libremente de la reflexión moral al exemplum: las discusiones de los cardenales sobre la elección del pontífice, el apoyo de los reyes europeos, son las tensiones que el Canciller señala como orígenes de esta encrucijada histórica. Esta crisis pone a la comunidad cristiana en una situación difícil en relación a las otras comunidades religiosas de la Península:

Los moros e judios rien d'esta contienda, en dizen entre si: «Verdes que leyenda tienen estos cristianos, e como su fazienda traen bien ordenada, jasi Dios los defienda!».

\footnotetext{
${ }^{32}$ La variedad de exempla presentes en el Rimado de Palacio ha sido estudiada en varias oportunidades. Véase Germán Orduna, «El concepto de enxienplo en la obra del Canciller Ayala», en Philologica Hispaniensia in honorem Manuel Alvar, Madrid, Gredos, 1987, III, pp. 305-308; íd., «Función de la materia ejemplar en el contexto del Rimado de Palacio», en Anclajes. Revista del Centro de Análisis del Discurso, 1:1 (1997), pp. 137-147; íd., «El enxemplo en la obra literaria del Canciller Ayala», en El arte narrativo y poético del Canciller Ayala, Madrid, CSIC, 1998, pp. 161-173 y Hugo O. Bizzarri, «Pero López de Ayala y la tradición del exemplum», en Formas narrativas breves. Lecturas e interpretaciones, ed. de Carlos Alvar, San Millán de la Cogolla, CiLengua, 2014, pp. 61-83. No debe dejarse de lado el siguiente trabajo dedicado a las crónicas, Alberto Várvaro, «Storiografia ed exemplum in Pero López de Ayala», en Medioevo Romanzo, 14 (1989), pp. 255-281.
} 
E dizen cada dia a nos que nos tornemos, aquella su ley santa e que la adoremos, e como la ellos guardan cuidan que non lo vemos, por ende, nos cuidamos que lo mejor tenemos (cc. 209-210).

En la sección que trata sobre la crisis de la cúpula del poder laico (cc. 234-259) coloca un exemplum sobre la avidez de los reyes (cc. 242-255): los huérfanos y los villanos son presa de la codicia de los reyes. Ellos se ayudan de la avidez de otro grupo social, los judíos:

Alla fazen judios el su repartimiento sobre el pueblo que muere por mal defendimiento, e ellos luego apartan entre si medio cuento que han de aver privados, cual ochenta, cual çiento (c. 242).

Cada exemplum denuncia la avidez del grupo social. El más destacado tradicionalmente sobre este aspecto es el de los mercaderes:

Una vez pidran çincuenta doblas por un paño, si vieren que estades duro e entendedes vuestro saño, diz': «Por treinta vos lo do», ¡mas nunca el cunpla el año, si non l' costo cuarenta ayer de un omne estraño!».

Diz': «Tengo escarlatas de Brujas e Mellinas, veinte años ha que non fueron en esta tierra tan finas»; diz': «Tomadlas vos, señor, antes que unas mis sobrinas las lieven de mi casa que son por ellas caninas».

«Si vos tenedes dineros, si non tomar he yo plata, ca en mi tienda fallaredes toda buena barata»; el cuitado que lo cree una vez con el se ata, a traves yaze caido, si delante non se cata.

Non se tienen por contentos por una vez doblar su dinero, mas tres tanto lo quiere amuchiguar, diz': «Somos en perigros por la tierra e por la mar, ca nos faze agora el rey otros diezmos pagar» (cc. 300-303).

El «Enxienplo del bachiller en leyes y decretales» (cc. 316-336) retrata el accionar de un bachiller en un pleito. La finalidad de este oficial de justicia es prolongar el juicio para sacar dinero al querellante. El pobre afligido no sólo 
tiene que darle su dinero, sino aún empeñar todo cuanto tiene: «[...] prometiole de dar la mula por seguir la apelaçion, / despues dize el bachiller: 'Prestadme vuestro manton, / ca el tienpo es muy frio, non muera por ocasion'» (c. $334 \mathrm{~cd}$ ). El bachiller le pide mil reales más, que el querellante debe dar para continuar con el juicio. Concluye el episodio:

El cuitado finca pobre, mas el bachiller se va, si no es nesçio o pataco nunca mas le perdera, asi pasa, ¡mal pecado!, e paso e pasara, quien me creer quisiere, de tal se guardara (c. 336).

Ayala coloca un segundo exemplum sobre la justicia: «El malfechor» (cc. 350-363) en el que presenta el caso de una persona condenada a muerte por robo. Si tiene algo con que pagar soborno, podrá escapar de prisión de noche (c. 351) o se lo excusará de muerte (c. 358), pero si no es este el caso, será condenado como traidor y ahorcado. Finalmente, un mercader paga al juez su liberación y este le ruega que lo oculte en su casa, pues todos deben creer que él está deseoso de hacer justicia (c. 363).

El último exemplum es el «Enxienplo de los arrendadores» (cc. 365-371) que cobran sus pechos ayudados por los judíos (cc. 365-366). Los abusos de estos funcionarios no se detienen en su avidez de dinero. Su apetencia de poder llega hasta apoderarse de las jóvenes del reino cuyo casamiento es ventajoso:

Si supiere en la villa, algunt casamiento fino, luego pone corredores e andan por el camino, e dizen: «Dadme esta moça para un moço mi sobrino, ca sienpre sera buen omne, yo lo veo en su signo.

Fijo es de una mia prima, mi parienta coronal».

Non ha con el mas debdo que en Roma cardenal, conviene que gela den, siquier' con bien o con mal, para costa de las bodas, sienpre les paga la sal (cc. 368-369).

La reflexión moral final también contiene varios exempla, el primero de ellos el «Enxienplo del caminante» (cc. 382-384): un caminante solitario va por el camino y se le acerca un ladrón proponiéndole su compañía en el viaje. Confía en él, pero cuando se duerme, el ladrón huye robándole su mula y sus paños. Con este ejemplo Ayala pretende ilustrar cómo los vicios (que él llama 'tachas') roban las virtudes al hombre. A diferencia de los exempla colocados 
en la crítica a los estados, que se caracterizan por su carácter dramático, este ejemplo es esencialmente narrativo.

En el poema Rogaría los exempla son de carácter hagiográfico: recuerda el sacrificio de niños mártires (cc. 416-418). Ayala muestra que Dios no abandona a los suyos y que el sacrificio de estos inocentes fue luego recompensado con la salvación.

La crítica a los estados es rica en exempla, aunque ellos siempre respondan a un mismo tipo: el exemplum dramatizado, lo que entre los predicadores se llamaba 'Plática' ${ }^{33}$. Hay exempla que se unen fácilmente a la tradición de los états $d u$ monde, como son «Los mercaderes», «El bachiller en leyes $\mathrm{e}$ decretales» o «El malfechor». Otros responden a una innovación de Ayala en su personal visión de los estados, como el «Enxienplo de la elección de Urbano IV». Pero todos responden a una observación concreta de la realidad inmediata. Ayala reúsa hablar de los judíos, retratados tradicionalmente como prestamistas y acusados de usura, pero los coloca por doquier. Ellos son una de las plagas de Castilla: enemigos de la cristiandad la atacan debilitada por el Cisma, colaboran en el cobro de pechos excesivos y son una de las causas de la despoblación del reino ${ }^{34}$. Así se sirve Ayala en su examen de la realidad castellana del siglo XIV del género de los états du monde.

\section{Conclusión}

Como se ha visto, la descripción que hace Ayala de la sociedad de su tiempo, aunque es personal, se basa en la larga tradición de los états du monde. La desatención de este aspecto y la instrucción clerical del canciller condujeron a Strong a buscar el modelo de la sátira ayalina en el tratado de Perrault. Pero es que tanto el tratadista latino como López de Ayala se anclan en una misma tradición. Un tipo de literatura que, como bien señaló Mohl, gozó de una expansión enorme en toda la Europa medieval. Ella es un ejemplo más del espíritu europeizante del canciller (y embajador) López de Ayala que supo mirar la crisis castellana con una perspectiva universalista.

Recibido: 20/03/2015

Aceptado: 18/05/2015

\footnotetext{
${ }^{33}$ Bizzarri, ob. cit., pp. 74-75.

${ }^{34}$ Ya José Amador de los Ríos en su Historia social, política y religiosa de los judios de España y Portugal, Madrid, Imprenta de T. Fortanet, 1876, II, pp. 228-232, esbozó la visión de los judíos que presenta Ayala.
} 
LA TRADICIÓN DOCTRINAL Y EJEMPLAR DE LOS ÉTATS DU MONDE EN EL RIMADO...

\title{
$\cos$
}

\section{LA TRADICIÓN DOCTRINAL Y EJEMPLAR DE LOS ÉTATS DU MONDE en el Rimado de Palacio de Pero López de Ayala}

\begin{abstract}
Resumen: Las coplas 191 a 728 del Rimado de Palacio desarrollan una crítica a la sociedad del siglo XIV que los estudiosos han considerado inspirada en la Summae virtutum et vitiorum de Guillermo Perrault. Sin embargo, lo que hace aquí Ayala es retomar un tipo de literatura muy difundido en Francia, el género de los États $d u$ monde. En el presente artículo, se describe la poética de este género y cómo Ayala la adecua a la realidad de la Castilla del siglo XIV.
\end{abstract}

Palabras clave: Estados. Estamentos sociales. Sátira. Rimado de Palacio. Pero López de Ayala.

The exemplar and doctrinal Tradition of The États DU MONDE in the Rimado de Palacio of Pero López de Ayala

\begin{abstract}
The couplets 191 to 728 of the Rimado de Palacio display a critic of the society in the $14^{\text {th }}$ century, which scholars have considered inspired in Guillermo Perrault's Summae virtutum et vitiorum. Nevertheless, what Ayala is doing here is retaking a kind of literature which was to a great extent widespread in France, the genre of the Etats $d u$ monde. This paper intends to describe the poetics of this genre and to show the way in which Ayala adapts it to the reality of the $14^{\text {th }}$ century Castile.
\end{abstract}

Keywords: Estates. Social class. Satyre. Rimado de Palacio. Pero López de Ayala. 